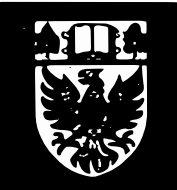

\title{
THE COST OF EQUITY CAPITAL: A RECONSIDERATION
}

By

\section{M.J. GORDON}

Professor of Finance University of Toronto

and

\section{L.I. GOULD}

Assistant Professor of Finance McMaster University

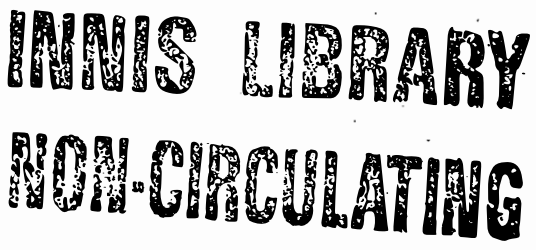

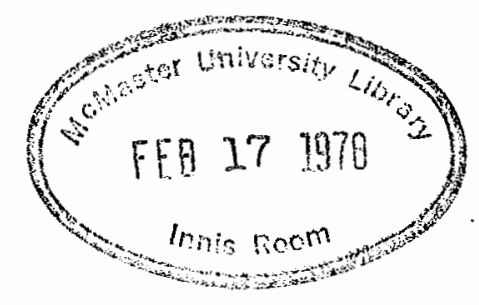

Innis

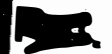

$\mathrm{HB}$

74.5

R47

no.140 
The Cost of Equity Capital: A Reconsideration

M.J. Gordon and L.I. Gould*

In the early sixties a number of papers developed stock value models in which the cost of equity capital is a function of the firm's equity investment rate. The conclusions reached, however, have for the most part been rejected in the subsequent literature. Instead, it has become widely accepted both in the theoretical work and in the textbooks on finance that the cost of equity capital is equal to the yield at which a firm's stock is selling, and the latter is independent of the firm's investment rate. In fact, one frequently finds the two terms, share yield and cost of equity capital used interchangeably in the literature. However, contributions to the literature during the last few years provide additional support for and clarification of the alternative theory, and a broad reconsideration of the subject is in order.

Part I below critically reviews the literature of the early sixties on both sides of the subject and certain subsequent papers which contributed to the conclusion that share yield and cost of equity capital are equal and independent of investment policy. Parts II and III examine the recent contributions which have materially strengthened the theoretical basis for the contrary conclusion, that the cost of equity for a firm is an increasing function of its investment rate. Part IV reviews the empirical evidence on the subject, and Part $V$ both summarizes the conclusions reached and discusses the areas in which the model requires further development.

* The authors are Professor of Finance, University of Toronto, and Assistant Professor of Finance, McMaster University, respectively. 
A. The Original Model

In the early sixties Gordon [14][15] and Lintner [22][23] examined the implications for the cost of capital of the constant expected growth rate stock value model,

$$
P=(1-b) Y /(k-b r)
$$

In this equation

$$
\begin{aligned}
P= & \text { Present value of the firm's stock. } \\
Y= & \text { Expected value of the firm's earnings in the coming year. } \\
\mathrm{b}= & \text { Expected value of the firm's investment and retention rate } \\
& \text { for the indefinite future. } \\
\mathrm{r}= & \text { Expected value of the return on investment with investment } \\
& \text { the fraction } b \text { of earnings. } \\
\mathrm{k}= & \text { Required return or yield at which the stock is selling. }
\end{aligned}
$$

The derivation of Eq. (1) is explained in the above references.

In the development of this model the authors made the assumptions necessary to equate investment policy with dividend policy - no stock financing and a constant debt equity ratio. ${ }^{1}$ The former assumption will be withdrawn shortly, and the latter certainly does not limit the usefulness of the model.

If $r$ and $k$ are both functions of $b$, the partial derivative with respect to $b$ is

$$
\frac{\partial P}{\partial b}=\frac{Y}{(k-b r)^{2}}\left[-k+b r+(1-b)\left(r+b \frac{\partial r}{\partial b}-\frac{\partial k}{\partial b}\right)\right]
$$

${ }^{1}$ Gordon [15, p. 39] stated explicitly that "The consequence of these three assumptions is that an investor's estimate of b, a corporation's retention rate, implies an estimate of its investment rate." The third assumption was that in arriving at $P$ investors assume that a corporation will earn $r$ and retain $b$ in every future period. 
In the above $r^{\prime}=r+b \partial r / \partial b$ is the marginal rate of return on investment when investment is at the rate b. Setting Eq. (2) equal to zero and solving for $r^{\prime}$ we find that the value of $P$ is maximized when $b$ is set so that

$$
r^{\prime}=(k-b r) /(1-b)+\partial k / \partial b
$$

is satisfied.

The left hand side of Eq. (3), the marginal rate of return on investment, is a decreasing function of b, the firm's investment rate. The right hand side of Eq. (3) may properly be called the firm's cost of capital, since the term cost of capital is a short-hand expression for the discount rate a firm should use in deciding whether or not undertaking an investment will raise the value of a firm's stock. If the value of $r^{\prime}$ at some investment rate is above the right hand side of Eq. (3), undertaking the next most profitable investment will raise the value of the firm's stock. and vice versa. $P$ is maximized at the value of b which satisfies Eq. (3).

It is clear that the cost of capital given by Eq. (3). is not independent of $b$. If $k$ is independent of $b$, the curve $(k-b r) /(1-b)$ first falls and then rises as b increases. Also, $P$ is maximized when (k-br)/(1-b), the earnings yield, is minimized. The relations among the variables $r, r^{\prime}, k,(k-b r) /(1-b)$ and $b$ are illustrated in Figure I. Notice that at $b *$, the optimal investment rate, $\mathbf{r}^{\prime}<\mathrm{k}$ and $\mathbf{r}>\mathbf{k}$.

The values of $k$ and $(k-b r) /(1-b)$ in Figure $I$ assume that $\partial k / \partial b=0$. With $\partial k / \partial b>0$, the cost of capital may well rise continuously with $b$ because $\partial k / \partial b>0$ and because $k$ in $(k-b r) /(1-b)$ is rising with $b$. This subject will be considered further in Part II. 
Figure I

Returns, Share Yield, and the Marginal Cost of Capital

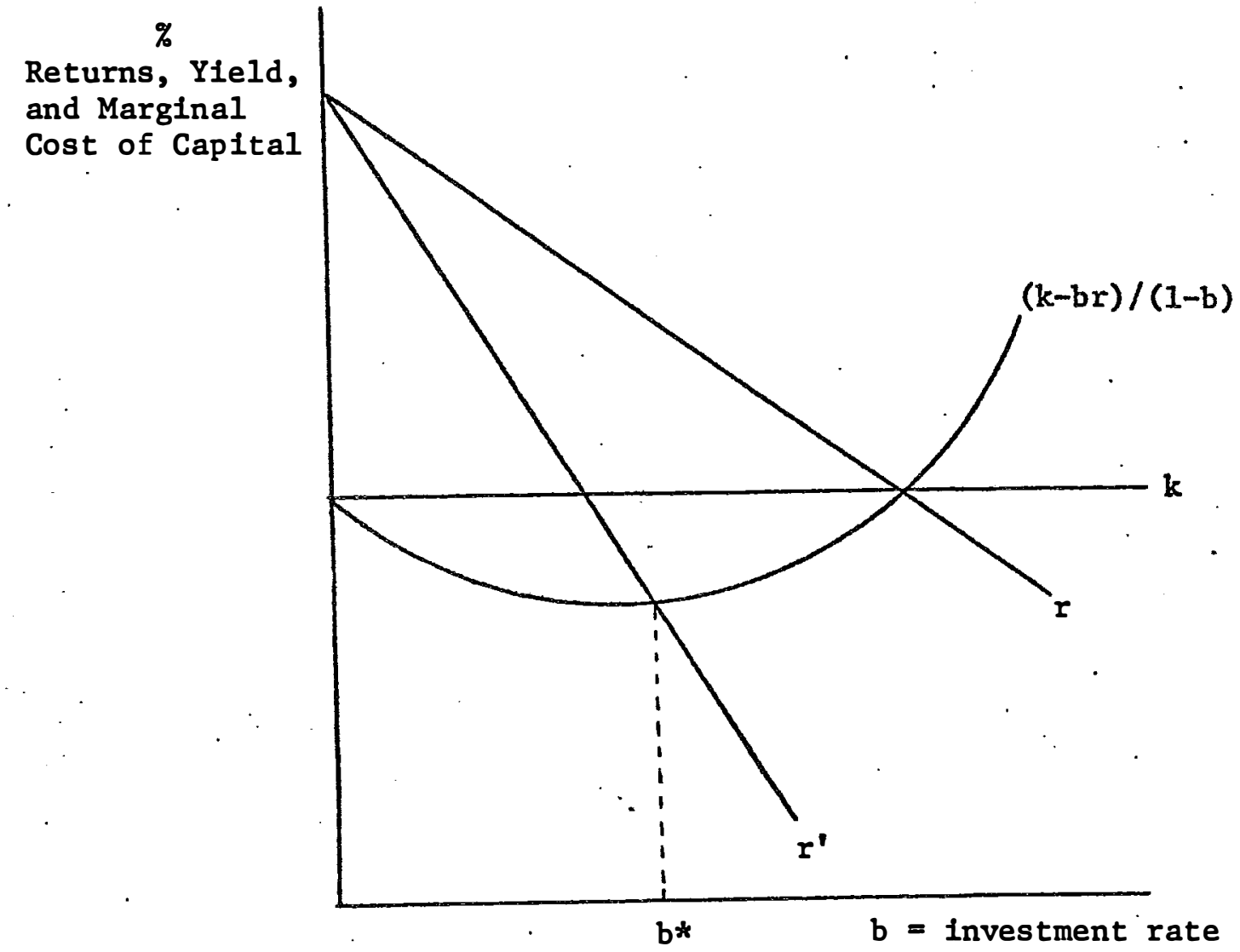


B. Dividend Policy versus Investment Policy

Before proceeding, it should be noted that the model is easily generalized to allow stock as well as retention financing of investment. Let $g=$ the expected rate of growth in the dividend to a current share, In which case Eq. (1) becomes

$$
P=(l-b) Y /(k-g)
$$

Miller and Modigliani [25, p. 423] have shown that with s the stockfinanced investment expressed as a fraction of earnings,

$$
g=[(b+s) r(1-b)-s k] /(1-b-s)
$$

Substituting this expression for $g$ in Eq. (4) and simplifying results in

$$
P=(1-q) Y /(k-q r),
$$

where $q=b+s$ is the firm's investment rate.

Taking the derivative $\partial \mathrm{P} / \partial \mathrm{b}$ or $\partial \mathrm{P} / \partial \mathrm{s}$ holding $\mathrm{q}$ constant reveals that they are each equal to zero. Dividend policy per se has no influence on share value and the cost of capital. ${ }^{1}$ However, taking the derivative $\partial P / \partial q$ produces Eq. (3) with the investment decision replacing the retention decision.

The Miller and Modigliani [25] paper on dividend policy is the primary theoretical basis for the widespread acceptance of the proposition that the cost of equity capital is equal to the yield at which the company's stock is selling. What this paper established is that with

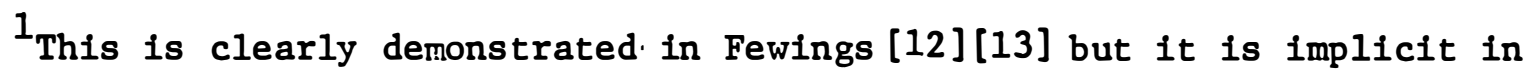
the analysis of stock financing in Gordon [14, Ch. 9]. 
no transaction costs and no taxes, the value of a firm is independent of the allocation of its financing between retention and the sale of stock. We agree that with no taxes, no transaction costs and no informational content to the dividend, the choice between retention and the sale of stock to finance a given investment plan is of no consequence to a firm.

However, a firm still has the problem of arriving at its investment plan, and the Miller-Modigliani paper had absolutely nothing to say on this subject. The analysis of that problem by other writers was disposed of with the statement, "...the argument clearly suffers fundamentally from the typical confounding of dividend policy with investment policy that so frequently accompanies use of the intermal financing model." [25, p. 425]. What should have been clear is that the Miller-Modigliani paper and the previously cited papers by Gordon and Lintner were concerned with two different problems. Miller and Modigliani were concemed with choice between the two sources of equity funds under assumptions which clearly made the choice of no consequence. ${ }^{1}$ Gordon and Lintner were concerned with what the investment plan should be under the same assumptions - no transaction costs, no personal income tax and no informational content to the dividend. In their papers these assumptions were made explicitly or implicitly to abstract from issues that were not relevant to the non-trivial problem under consideration, the optimal investment decision.

\footnotetext{
${ }^{1}$ The rigorous proof in their paper that the choice is of no consequence is nonetheless of some value insofar as it provides a reference base for going forward to investigate the real problems - transaction costs, differential taxation, information content of the dividend and most of all investment policy.
} 


\section{The Return on Investment Function}

Let us turn now to the more substantial criticisms of the Gordon-Lintner theory of the cost of equity capital. Looking back at Eq. (3) we see that with $k$ independent of $b$ but $r$ the function of $b$ that gives rise to Eq. (3), the cost of retention capital is (k-br)/(1-b), a function of $b$. For $(k-b r) /(1-b)$ to be the cost of equity capital, the return on investment expressed as a function of $b$ in every future period must be the same and independent of $b$, which means that the return as a function of the level of investment shifts upward at a constant rate that increases with the value of br. ${ }^{1}$ In a comment on one of Lintner's papers Miller [24] argued that this return on investment function has little if any empirical relevance. We will examine Miller's objections to this. property of the retum on investment function in the next section.

The work of Gordon and Lintner was integrated, and in some respects carried forward by Lerner and Carlton [21]. They developed an investment decision model in which the return on investment function has the properties described above and the required return is an increasing function of the growth rate. However, they provided no new empirical evidence and their theoretical argument seemed to have been no more convincing than the previous efforts. In addition their argument was marred by an error that was commented on by Ben-Shahar and Ascher [3] and Crockett and Friend [9]. ${ }^{2}$ The latter comment was the clearest statement of the problem and the issues to date, but the authors were not persuaded there was any merit in the critical assumptions of the theory--the return on investment function and the relation between $k$ and growth.

\footnotetext{
$1_{\text {This property }}$ of the return on investment function was first noted by Bodenhorn [5].

2

Lemer and Carlton confused the return on the existing assets with the firm's return on investment. A stockholder may use one to estimate the other, but the firm can't make its investment decision on the assumption that they are equal.
} 


\section{The Behavior of Share Yield}

With regard to the proposition that a share's yield is an increasing function of the firm's investment rate, Gordon [14] argued that a share's yield is a weighted average of the sequence of discount rates, $k_{t}, t=1 \rightarrow \infty$ used to discount each future dividend, the risk of a dividend increases with its date in the future, and therefore the $k_{t}$ might well increase with the rate of growth in the dividend. Higgins [19] showed that the independence of the value of the firm from its rela,tive use of retention and stock financing under the Miller-Modigliani assumptions holds when the future'dividends are discounted at different rates. However, Higgins was concerned with the exact same problem as MIller and Modigliani, and his analysis is irrelevant when investment is the decision variable.

However, a paper by Chen [7] cast serious doubt on the likelihood that $k_{t}$ increase with $t$. He showed that the risk of future dividends must increase at an increasing rate with time for $k_{t}$ to increase with $t$, and there seemed to be no a priori basis at the time for believing that dividend risk increases in this way with time. 1

Lintner [23] also presented a theoretical argument in support of the proposition that risk and $k$ increase with growth. We know of no efforts to disprove the reasoning under which he reached his conclusion. Perhaps the complexity of the argument is why it had so little impact on the subsequent literature.

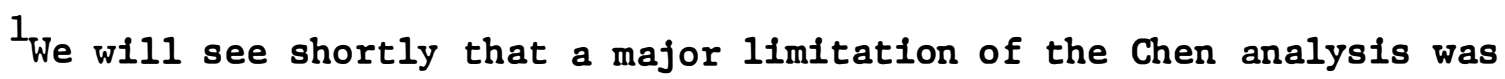
its fallure to recognize that the risk free interest rate increases with the time in the future of a certain payment. 
II

We have seen that either or both of two conditions make the cost of equity capital a function of the firm's investment rate. One condition is dependence of a share's yield on the investment rate. The other condition is dependence of the return on investment function in future periods on the firm's current investment decison.

\section{A. The Elton-Gruber Analysis}

An Ingenious paper by Elton and Gruber [10] models an exceptionally wide range of assumptions with regard to a firm's future rate of return on investment functions, and derives the value of the firm and its cost of capital for each of these functions under the assumption that $k$ is independent of the investment decision. For our purposes the results of this paper may be summarized as follows. First, if the return on investment function in each future period is independent of the firm's current investment decision, regardless of how these return on investment functions shift over time, a firm's cost of capital is $k$. That is, the firm's investment decision should equate the marginal rate of return on investment with the firm's share yield.

On the other hand, if the retum on investment function in period $f$ depends in some way on the investment decision in period t<f, then regardless of what this relation is, a firm's cost of capital depends on its investment decision and is not equal to $k$, even if $k$ is independent of that investment decision. Let us refer to a firm's return on investment function as 1 ) the absolute return on investment function when $r$ is expressed as a function of the dollar investment in a period and 2) as the relative return on investment function when $r$ is expressed as a function of $\dot{q}$, the investment divided by the earnings in the period. 
Eq. (1) is based on the assumption that the relative return on investment function in period $\mathrm{J}$ is independent of the investment decision in prior periods. This means that the absolute return on investment function shifts outward at a constant rate over time with the shift rate equal to the product $q r$. Hence, as has been noted in earlier papers, raising $q$ raises the investment opportunities available in future periods as long as $q r$ rises with $q$. It therefore pays a firm to set the investment at a level at which $r^{\prime}<k$.

In the other mode!ls explored by Elton and Gruber in which the future return on investment functions depend on current investment, the cost of capital is also not equal to $k$. It varies with the investment rate but not with the product $q r$, and whether or not the cost of capital at the optimal $q$ is above or below $k$ depends on the model chosen. Therefore, a necessary condition for a firm's cost of capital to be equal to $k$ is that a firm's absolute return on investment function in each future period is independent of its prior investment decisions.

\section{B. The Miller Criticism}

Let us now take up the criticism by Miller of the plausibility of the independence of the relative return on investment function assumed in Eq. (1). Miller's criticism of the model began with a reference to the "IBM paradox." "That is, if the current earnings yield on IBM is, say 2 per cent, then some student can invariably be found who will seriously suggest that the company ought to undertake any investment which promised to yield at least 2 per cent plus epsilon." [24, p. 314]. This objection to the model is probably the major reason for the decline of interest in 1t. After all, in the early sixties we had fust established that the yield at which a share sells is $k=(1-b) Y / P+g$ and not the earnings yield. To immediately turn around and argue that nonetheless 
the earnings yield should be used as the cut-off rate in capital budgeting undoubtedly seemed a little embarrassing particularly when It produced such bizarre results. We will see shortly that a complete model of share valuation does not produce such bizarre results.

However, Miller did not use the "IBM paradox" to reject the model. He acknowledged that undertaking investments with a 2 per cent return Is justified when "...under Lintner's dependence assumption, they also shift the investment-productivity schedule in every future period upward and to the right..." [24, p. 315].

Miller went on to refer to this capital budgeting criterion as "a verbal trick resulting from his use of the term 'marginal rate of return on investment' to refer only to the direct return of the low-yielding, 'loss-leader' projects." [24; p. 315]. It is true that If we include the added returns on future investment projects made possible by the current investment project in the latter's cash flow, the cut-off rate should be $k$ and not the eamings yield on the share. It is also true as Miller Implicitly concedes that if the excess returns on future projects generated by the current investment are not included, the cut-off rate is the eamings yield. What would be incorrect is to use $k$ as the cut-off rate and only include the cash flows directly attributable to the current project in arriving at its internal rate of return. The choice between the two correct approaches, therefore is a matter of convenience and not semantics or trickery. 1

The fundamental issue, therefore, is whether or not the absolute return on investment function in a period is independent of, or shifts upward with, the size of the firm's prior investment decisions. Miller concludes his discussion with a rejection of dependence, using an appeal

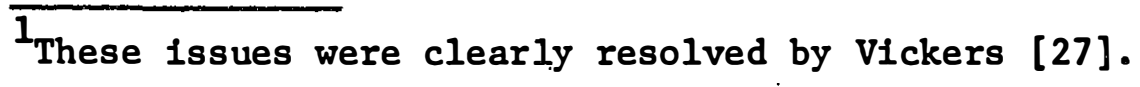


to common sense to fustify the conclusion. He wrote "The dependence assumption, for example, requires one to belleve that, even though IBM would earn only 2 per cent on a new factory to produce obsolete 650's the construction of such a plant would automatically make it possible to expand the capacity for 7090 's on which the company earns 40 per cent!" [24, p. 315]. On the other hand, the position that the investment opportunities avallable to IBM, General Motors or any other f1rm are Independent of their prior investment decisions means that IBM and General Motors would have the same investment opportunities today if they had undertaken no investment over the prior fifty years. What could be less true?

In fact, we may go on to note that a sufficient if not a necessary condition for perfect competition is independence of investment opportunities of prior investment decisions - or more generally of an Individual's or firm's history. 'Clearly such independence exists with regard to the investment in publicly traded shares by individuals. However, having it exlst in general would imply that everyone born in the United States has the same opportunity to become the president of the country, not as an abstract political right but as a technological possibility. Clearly our investment and our employment opportunities depend on our history. 1

It does not follow that the exact form of the dependence assumed In Eq. (1) is correct. As Elton and Gruber [10] have shown, a wide range of possibilities with regard to the functional form of the dependence exist. However, the assumption that the investment opportunities grow at the rate $q r$ is the most plausible, simple, and

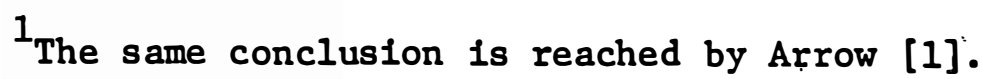


analytically tractable among those considered by Elton and Gruber. ${ }^{1}$ This only suggests that it be given serious consideration, with its ability to describe and produce correct decisions empirically as the further test to be satisfied.

III

With regard to the relation between share yield and a firm's investment rate, an important contribution was made by Fewings [12][13]. ${ }^{2}$ In [13] he showed that with the'end-of-period value of $k$ uncertain, but with. the firm's rate of return on investment certain, the risk of the holding period return on a share is an increasing function of its investment rate. The argument can be stated quite briefly as follows.

\section{A. The Fewings Model}

One plus the holding period retum on a share during $t$ is

$$
R_{t}=\left(D_{t}+P_{t}\right) / P_{t-1}
$$

with $D_{t}$ the dividend during $t$, and $P_{t-1}$ and $P_{t}$ the share's price at the start and end of $t$. With $g_{t}$ the rate of growth in the dividend, $k_{t}$ the share's yield at the end of $t$, and $P_{t}=D_{t+1} /\left(k_{t}-g_{t}\right)$, Eq. (7) may be written as follows:

1'The alternative explored by them is to have the shift in the return function a function of $r$. Since $r$ is an inverse function of $q$, either can be taken as the independent variable. It would appear more reasonable to make the independent variable the product $q r$, since the shift in the investment opportunities function is favorable as long as $q r$ increases with $q$, and it becomes unfavorable when the decline in $r$ offsets the rise in $q$.

2 Haugen and Wichern [18] and Boquist, Racette and Schlarbaum [6] have shown that the risk of a bond increases with its duration or growth. Fewings went beyond this conclusion to establish the interrelations among risk, growth, investment rate and financing policy for a firm's common equity. His work, therefore, leads to conclusions on the influence of growth and investment on a firm's cost of capital. 
$R_{t}=\left[D_{t}+\frac{D_{t+1}}{k_{t}-g_{t}}\right]\left[\frac{k_{t-1}-g_{t-1}}{D_{t}}\right]$.

Eq. (5) with the variables which may change over time subscripted is

$$
g_{t}=\frac{\operatorname{qr}(1-b)-s k_{t}}{1-q}
$$

Note that at the start of $t, D_{t+1}=_{t}\left(1+g_{t}\right), r$ is certain, $k_{t-1}$ is known, and $q, b$ and $s$ are decision variables. $k_{t}$ and $g_{t}$ are uncertain, the latter because $k_{t}$ enters into the determination of $g_{t}$. Substituting Eq. (5a) for $g_{t-1}$ and $g_{t}$ in Eq. (8) and simplifying results in

$$
R_{t}=1+k_{t-1}+\frac{\left(k_{t-1}-k_{t}\right)(1+q r)}{k_{t}-q r}
$$

The only random variable in this expression is $k_{t}$, and the value of Beta for the share at the start of $t$ is

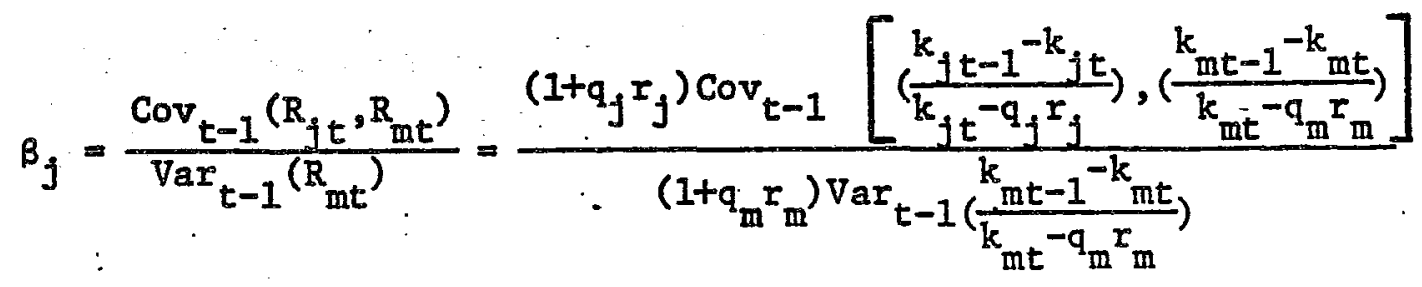

It is clear that if $k_{j t}$ and $k_{m t}$ are correlated $\operatorname{Cov}_{t-1}\left(R_{j t}, R_{m t}\right)$ is positive, and the risk of the share increases with $q_{j}$, the firms investment rate. The presence of $q$, outside and inside the covariance expression both contribute to the increase in $\beta_{j}$ with $q_{j}$.

In [12] Fewings allowed $r_{t}$ as well as $k_{t}$ to be random variables. The above conclusion is reached both with $r_{t}$ equal to the realized value In the period fust ended and an exponential average of the past realized values of the rate of return. The conclusion holds with q=b+s applied to actual earnings during the period and under the more realistic 
assumption that the dividend rate is applied to expected earnings at the start of each period. If risk or $\beta$ increases with the firm's investment rate, share yield is positively correlated with the investment rate and $\partial k / \partial q>0$.

\section{Multi-Period Consumption Models}

Notice that the Fewings model combines the Gordon-Lintner intrinsic value model and the Sharpe-Lintner-Mossin (SLM) capital asset pricing model. Fewings obtained his results by replacing the end-of-period share price in the SLM model with the Gordon-Lintner expression for share price. It has been suggested to us that a recent paper by Fama [11] established that doing so is wrong. In fact, the Fama paper is wrong or at the very least so confusing in its choice of language as to lead to this inference about the Fewings model.

Fama stated that the purpose of his paper is to establish the "... limitations imposed by the SLB model on the admissible sources of uncertainty in the variables and parameters of the multiperiod valuation equation." (p.3). He went on to say that there can be no,

....uncertainty about the future values of 'market parameters' like the risk-free rate of interest and the market price of risk since the multiperiod version of the SIB model in general requires that these market parameters evolve deterministically. .....Second, the SLB model implies restrictions on the nature of uncertainty about the reassessments through time of the probability. distribution of a cash flow. .... The assumption that the pricing process follows the Sharpe-LintnerBlack model requires that, properly normalized, these covariances and the risk-adjusted discount rates that they imply must be known or nonstochastic at all relevant earlier points in time. (p.4).

What Fama actually did establish may be stated more accurately as fol-

lows. Let us abandon the SLM assumption that the investment decisions of investors are made with the objective of maximizing the utility of end-ofperiod wealth. Assume instead that they maximize the utility of their multiperiod consumption. What are the conditions under which the SLM capital asset pricing model expression for the yield at which a share sells still holds? Fama's answer to that question is the previously mentioned 
restrictions on future discount rates, on the reassessment through time of the probability distribution of future cash flows, etc.

However, the Fewings analysis employed the SLM capital asset pricing model. That model imposes no restrictions whatsoever on the properties of the cash flows or the discount rate that generate the end-of-period price In the model. The end-of-perlod price of a share in SLM is a black box that may be represented by any function one chooses, certainly by the Gordon-Lintner share value model.

It can be argued that the SLM end-of-period wealth utllity function is less reasonable than a mult1-period consumption utility function. But, we all know that a model or theory should not be judged solely if at all by the reasonableness of 1 ts assumptions. Insofar as the SLM model or its comblnation with Gordon-IIntner by Fewings generates interesting and empirically true statements about the world, we may properly use the theory even though we may be uncomfortable about some of its assumptions. A proper use of capital asset pricing models based on a mult1-period consumption function Is to discover more powerful explanations of share yleld, corporate investment behavior and related questions, rather than to categorically reject findings based on the SIM model.:

\section{IV}

\section{A. Review of the Evidence}

The previous pages have developed a model of stock valuation for arriving at the equity financing and investment decision which maximizes the value of the existing common equity. The central issues in the development of the model were (1) the relation between the yield on a share and the firm's investment rate, and (2) the relation between a firm's return on investment function in future periods and the firm's current investment decision.

On the first issue, the recent work of Fewings provides the 
theoretical basis for the conclusion that the required yield on a share increases with the investment rate. ${ }^{1}$ There is no lack of empirical evidence in support of this conclusion. Brigham and Gordon [7], Gordon [16] and others have found very strong inverse correlation between dividend yield and expected dividend growth. Brennan and Sharpe and Sosin [26] have found high inverse correlation between dividend yield and Beta. 2 Putting these two pieces of evidence together, we have positive correlation between growth and Beta or risk. Direct evidence on the correlation between Beta as a measure of risk of a firm's stock and its investment rate is reported in Gordon [16, pp. 122-8], Fewings [12] and Bar-Yosef and Kolodny [2]. 3

On the second 1ssue, we saw from the work of Elton and Gruber [10] that one cannot arrive at the influence of a firm's investment decision on the value of its stock without making some assumption about how the investment decision will influence the profitability of future investments. The two alternatives here are that a firm's absolute retum on investment function is independent of its current investment decision, and that the absolute return function is dependent on the current investment decision. It has been shown that between these two assumptions only the latter is at all plausible, in which case the cost of equity capital depends on the firm's investment decision apart from the previously discussed risk influence.

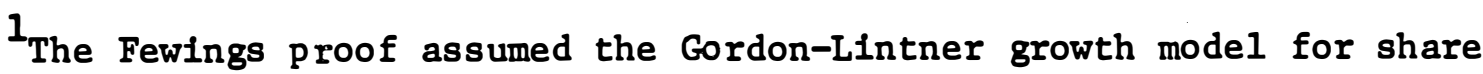
valuation. Whether or not the conclusion holds under more general assumptions remains to be seen.

2 Brennan's results are described by Jensen [20]. Since the personal income tax creates a tax preference in favor of high retention and growth stocks, the inverse relation between dividend yield and Beta is quite remarkable. It means that the total pre-tax retum investors require on a share increases with the fraction received in the form of capital gains due to the increased risk notwithstanding the tax consequences.

3 ${ }^{3}$ Black and Scholes [4] claim that the data reveals no relation among dividend yield, risk and return. However, their analysis of the data is beyond our comprehension. 
However, the Gordon-Lintner growth model makes the strong assumption that the form of the dependency is such that a firm's relative return on investment function is independent of its prior investment decisions. We know that this assumption is wide of the mark for some firms and is not strictly true for any firm. Nonetheless, its intuitive appeal, simplicity, and power compel attention. Furthermore, under a widely respected theory of knowledge, the test of a theory is not the accuracy of its assumptions but its accuracy in explaining and predicting variables of interest. Our . model has been found quite useful in measuring share yield, and it has met with some success in explaining investment behavior.

\section{B. Resolution of the IBM Paradox}

Let us now turn our attention back to the complete expression for the optimal investment decision

$$
r^{\prime}=\frac{k-q r}{1-q}+\frac{\partial k}{\partial q},
$$

with $q$ the investment decision and not merely the retention decision. With $k$ an increasing function of $q r$, the right hand side of Eq. (11) lies above the earnings yield, both because $\partial \mathrm{k} / \partial \mathrm{q}$ is positive and because $k$ in $(k-q r) /(1-q)$ increases with $q r$.

To use this expression, however, we must specify how $k$ varies with q. To test the conflicting hypothesis with regard to the relation between $k$ and $g=q r$ Brigham and Gordon [7] ran the regression 1

$$
D / P=\alpha_{0}+\alpha_{1} g+\ldots
$$

It was shown in [7] that if $k$ is independent of growth, $\alpha_{0}$ is an estimate of $k$ and we should find $\alpha_{1}=-1$. Instead we found $\alpha_{0}$ less than $k$ by all

\footnotetext{
$\mathbf{1}_{\text {The }}$ regression model included additional risk variables fow leverage, pretax earnings instability, and percentage electricity sales of total sales.
} 
reasonable standards and $\alpha_{1}>-1$ with a very high degree of statistical significance.

An alternative model is

$$
Y(1-q) / P=\alpha_{0}(1+q r)^{\alpha} 1 \text {. }
$$

Eq. (13) simply states that the price investors are willing to pay for a share increases with the growth in total dividends in a manner that makes $\mathrm{Y}(1-\mathrm{q}) / \mathrm{P}$ asymptotically approach zero. A variant of Eq. (13) was tested by Brigham and Gordon [7] and Gordon [16], and estimates of the coefficients were obtained. ${ }^{1}$

Adding qr to both sides of Eq. (13) results in

$$
Y(i-q) / P+q r=k=\alpha_{0}(1+q r)^{\alpha} 1+q r
$$

Taking the derivative of Eq. (14) with respect to q gives

$$
\frac{\partial k}{\partial q}=\alpha_{1} \alpha_{0}(1+q r)^{\alpha_{1}-1} x^{\prime}+r^{\prime} \text {. }
$$

Substituting this expression for $\partial k / \partial q$ in Eq. (1i) and simplifying results in

$$
x^{\prime}=\frac{k-q x}{1-q}\left[\frac{1}{-\alpha_{1} \alpha_{0}(1+q r){ }^{\alpha_{1}-1}}\right] \text {, }
$$

and noting that $\mathrm{k}-\mathrm{qr}=\alpha_{0}(1+\mathrm{qr})^{\alpha_{1}}$ we obtain

$$
r^{\prime}=\frac{1+q r}{-\alpha_{1}(1-q)}
$$

Possible ranges for the variables in Eq. (17) are $8<-\alpha_{1}<25$, and $.02<q \mathrm{q}<.15$.

$1_{\text {The model tested did not include stock financing, and therefore was }}$

$$
Y(1-b) / P=\alpha_{0}(1+b r)^{\alpha} 1
$$

with the additional risk variables described previously. Empirically the difference between $q$ and $b$ is negligible for purposes of parameter estimation. 
We have resolved the so-called IBM paradox. Assuming that $k$ is Independent of $q$ resulted in an unreasonably low cut-off rate for IBM's equity Investment rate in the early sixt1es. Recognizing that $k$ is an increasing function of $q$ substantially raises the cut-off rate. Assume that $-\alpha_{1}=20$. If the price of IBM stock was maximized at $q=.7$ with $q r=.21$ the cut-off rate for that company as determined by Eq. (17) was about a $20 \%$ return on investment.

\section{$\mathbf{V}$}

In conclusion, we would be the last to argue that the investment model described above is completely adequate. A particularly desirable extension is the identification and correct treatment of investment opportunities which do not satisfy the assumption that the firm's relative return on investment function is independent of prior investment decisions.

However, this is not the only limitation of the model, and it may not be the most important of the limitations. We have assumed a fixed debt-equity ratio, and insofar as the ratio may be changed, particularly In the short run, the model does not establish the optimal investment and equity financing decision. It was assumed that there is no informational content in a firms dividend decision with regard to current eamings. More generally, it was assumed that there is no problem in communication between the management and the stockholders of a firm. Finally, we have assumed that there is no personal income tax. ${ }^{1}$

It should be added that we have taken as the objective of a firm's management the maximization of the market value of the existing common equity. A management may also have other goals such as the long run survival and growth of the firm, and the management may be able to strike a compromise among these goals. Insofar as that is true, the accuracy of our model in explaining the price of a share fis not impaired, but the 
accuracy of the model in predicting the firm's investment decision is Impaired.

Finally, we conclude with a brief comment on growth. It is well known that corporate managements make a satisfactory rate of growth one of the seemingly independent objectives of the firm. This has led some writers to develop models of the firm in which management's goal is the maximization of the rate of growth in sales, subject to a profit constraint. We now see that such caricatures of corporate managements are not necessary to explain their behavior. Concern with growth may arise from the psychic and other rewards to management of a firm which offers opportunities for advancement to subordinates and themselves. However, concern with growth, not maximum growth, is also a consequence of a relative return on investment function that is independent of prior investment decisions. 
REFERENCES

1. Arrow, K.J., "The Economic Implications of Learning by Doing," Review of Economic Studies (June 1962): 155-73.

2. Bar-Yosef, S. and Kolodny, R., "Dividend Policy and Capital Market Theory," Review of Economics and Statistics 58 (May 1976): 181-90.

3. Ben-Shahar, $\mathrm{H}$. and Ascher, A., "The Integration of Capital Budgeting and Stock Valuation: Comment, American Economic Review 57 (March 1967): 209-214.

4. Black, F. and Scholes, M.; "The Effects of Dividend Yield and Dividend Policy on Common Stock Prices and..Returns," Journal of Financial Economics (1974): 1-22.

5. Bodenhorn, D., "On the Problem of Capital Budgeting," Journal of Finance 14 (December 1959): 473-92.

6. Boquist, J.A., Racette, G.A., and Schlarbaum, G.G., "Duration and Risk Assessment for Bonds and Common Stocks," Journal of Finance 30 (December 1975): 1360-65.

7. Brigham, E.F. and Gordon, M.J., "Leverage, Dividend Policy, and the Cost of Capital," Journal of Finance 23 (March 1968): 85-105.

8. Chen, H., "Valuation Under Uncertainty," Joumal of Financial and Quantitative Analysis 2 (September 1967): 313-25.

9. Crockett, J. and Friend, I., "The Integration of Capital Budgeting and Stock Valuation: Comment," American Economic Review 57 (March 1967) : 214-20.

10. Elton, E.J. and Gruber, M.J.; "Valuation and Asset Selection Under Alternative Investment Opportunities," Journal of Finance 31 (May 1976) : 515-39.

11. Fama, E.F., "Risk-Adjusted Discount Rates and Capital Budgeting Under Uncertainty," Journal of Financial Economics 5 (August 1977): 3-24.

12. Fewings, D.R., Corporate Growth and Common Stock Risk: Theory and Evidence. JAI Press, 1978.

13. "The Impact of Corporate Growth on the Risk of Common Stocks," Journal of Finance 30 (May 1975): 525-31.

14. Gordon, M.J., The Investment, Financing, and Valuation of the Corporation. Homewood, I11.: Richard D. Irwin, 1962.

15. , "The Savings Investment, and Valuation of the Corporation," Review of Economics and Statistics 44 (February, 1962): 37-49. 
16. The Cost of Capital to Public Utility. East Lansing, Michigan, Michigan State University Press, 1974 .

17. Gordon, M.J. and Gould, L.I., "The Cost of Equity Capital with a Personal Income Tax," Working Paper, McMaster University, 1977.

18. Haugen, R.A. and Wichern, D.W., "The Elasticity of Financial Assets," Journal of Finance 29 (September 1974): 1229-40.

19. Higgins, R.C., "Dividend Policy and Increasing Discount Rates: A Clarification," Joumal of Financial and Quantitative Analysis 7 (June 1972): 1757-62.

20. Jensen, M.C., "Capital Markets: Theory and Evidence," Bell Journal of Economics and Management Science 3 (1972): 357-98.

21. Lerner, E.M. and Carleton, W.T., "The Integration of Capital Budgeting and Stock Valuation," American Economic Review 54

(September 1964): 683-702.

22. Lintner, J., "The Cost of Capital and Optimal Financing of Corporate Growth," Journal of Finance 30 (May 1963) : . 292-310.

23. " "Optimal Dividends and Corporate Growth Under Uncertainty," The Quarterly Journal of Economics 78 (February 1964): 49-95.

24. Miller, M.H., "Discussion," Joumal of Finance 18 (May 1963): 313-16.

25. Miller, M.H. and Modigliani, F., "Dividend Policy, Growth, and the Valuation of Shares," Journal of Business 34 (October 1961): 411-33.

26. Sharpe, W.F. and Sosin, H.B., "Risk, Return and Yield: New York Stock Exchange Common Stocks, 1928-1969," Financial Analysts Journal (1976): 33-42.

27. Vickers, D., "Profitability and Reinvestment Rates: A Note on the Gordon Paradox," Journal of Business 39 (July 1966): 
Faculty of Business

McMaster University

WORKING PAPER SERIES

101. Torrance, George W., "A Generalized Cost-effectiveness Model for the Evaluation of Health Programs," November, 1970.

102. Isbester, A. Fraser and Sandra C. Castle, "Teachers and Collective Bargaining in Ontario: A Means to What End?" November, 1971.

103. Thomas, Arthur L., "Transfer Prices of the Multinational Firm: When Will They be Arbitrary?" (Reprinted from: Abacus, Vo1. 7, No. 1, June, 1971).

104. Szendrovits, Andrew Z., "An Economic Production Quantity Model with Holding Time and Costs of Work-in-process Inventory," March, 1974.

111. Basu, S., "Investment Performance of Commori Stocks in Relation to their Price-earnings Ratios: A Text of the Efficient Market Hypothesis," March, 1975.

112. Truscott, William G., "Some Dynamic Extensions of a Discrete LocationAllocation Problem," March, 1976.

113. Basu, S. and J.R. Hanna, "Accounting for Changes in the General Purchasing Power of Money: The Impact on Financial Statements of Canadian Corporations for the Period 1967-74," April, 1976. (Reprinted from Cost and Management, January-February, 1976).

114. Deal, K.R., "Verification of the Theoretical Consistency of a Differential Game in Advertising," March, 1976.

114a. Deal, K.R. "Optimizing Advertising Expenditures in a Dynamic Duopoly," March, 1976.

115. Adams, Roy J., "The Canada-United States Labour Link Under Stress," [1976].

116. Thomas, Arthur L., "The Extended Approach to Joint-Cost Allocation: Relaxation of Simplifying Assumptions," June, 1976.

117. Adams, Roy J. and C.H. Rumme1, "Worker's Participation in Management in West Germany: Impact on the Work, the Enterprise and the Trade Unions," September, 1976.

118. Szendrovits, Andrew Z., "A Comment on 'Optimal and System Myopic Policies for Multi-echelon Production/Inventory Assembly Systems '," [1.976].

119. Meadows, Ian S.G., "Organic Structure and Innovation in Small Work Groups," October, 1976. 
120. Basu, S., "The Effect of Earnings Yield on Assessments of the Association Between Annual Accounting Income Numbers and Security Prices," October, 1976.

121. Agarwal, Naresh C., "Labour Supply Behaviour of Married Women - A Model with Permanent and Transitory Variables," October, 1976.

122. Meadows, Ian S.G., "Organic Structure, Satisfaction and Personality," October, 1976.

123. Banting, Peter M., "Customer Service in Industrial Marketing: A Comparative Study," October, 1976. (Reprinted from: European Journal of Marketing, Vo1. 10, No. 3, Summer, 1976).

124. Aivazian, V., "On the Comparative-Statics of Asset Demand," August, 1976.

125. Aivazian, V., "Contamination by Risk Reconsidered," October, 1976.

126. Szendrovits, Andrew Z. and George 0. Wesolowsky, "Variation in Optimizing Serial Multi-Stage Production/Inventory Systems, March 1977.

12]. Agarwal, Naresh C., "Size-Structure Relationship: A Further Elaboration," March 1977.

128. Jain, Harish C., "Minority Workers, the Structure of Labour Markets and Anti-Discrimination Legislation," March, 1977.

129. Adams, Roy J., "Employer Solidarity," March, 1977.

130. Gould, Lawrence I. and Stanley N. Laiken, "The Effect of Income Taxation and Investment Priorities: The RRSP;" March 1977.

131. Callen, Jeffrey L., "Financial Cost Allocations: A Game-Theoretic Approach," March 1977.

132. Jain, Harish C., "Race and Sex Discrimination Legislation in North America and Britain: Some Lessons for Canada," May, 1977.

133. Hayashi, Kṭchiro. "Corporate Planning Practices in Japanese Multinationals. Accepted for publication in the Academy of Management Journal in 1978.

134. Jain, Harish C., Ne1l Hood and Steve Young, "Cross-Cultural Aspects of Personnel Policies in Multi-Nationals: A Case Study of Chrysler UK", June, 1977.

135. Aivazian, V. and J. L. Callen, "Investment, Market Structure and the Cost of Capital", July, 1977. 
136. Adams, R. J., "Canadian Industrial Relations and the German Example", October, 1977.

137. Callen, J. L., "Production, Efficiency and Welfare in the U.S. Natural Gas Transmission Industry", October, 1977.

138. Richardson, A. W., "Cost-Volume-Profit Analysis and the Value of Information", November, 1977.

139. Jain, Harish C., "Labour Market Problems of Native People in Ontario", December, 1977. 


$$
\begin{aligned}
& \text { Jnnis } \\
& \text { REF } \\
& H B \\
& 74.5 \\
& \text { R47 } \\
& \text { no. } 140
\end{aligned}
$$

3 